\title{
De novo genome assembly of the soil-borne fungus and tomato pathogen Pyrenochaeta lycopersici
}

\author{
Maria Aragona ${ }^{1}$, Andrea Minio ${ }^{2}$, Alberto Ferrarini ${ }^{2}$, Maria Teresa Valente ${ }^{1}$, Paolo Bagnaresi ${ }^{3}$, Luigi Orrù ${ }^{3}$, \\ Paola Tononi², Gianpiero Zamperin², Alessandro Infantino' ${ }^{1}$, Giampiero Valè ${ }^{3,4}$, Luigi Cattivelli ${ }^{3}$ \\ and Massimo Delledonne $e^{2^{*}}$
}

\begin{abstract}
Background: Pyrenochaeta lycopersici is a soil-dwelling ascomycete pathogen that causes corky root rot disease in tomato (Solanum lycopersicum) and other Solanaceous crops, reducing fruit yields by up to $75 \%$. Fungal pathogens that infect roots receive less attention than those infecting the aerial parts of crops despite their significant impact on plant growth and fruit production.

Results: We assembled a 54.9Mb P. lycopersici draft genome sequence based on Illumina short reads, and annotated approximately 17,000 genes. The P. Iycopersici genome is closely related to hemibiotrophs and necrotrophs, in agreement with the phenotypic characteristics of the fungus and its lifestyle. Several gene families related to host-pathogen interactions are strongly represented, including those responsible for nutrient absorption, the detoxification of fungicides and plant cell wall degradation, the latter confirming that much of the genome is devoted to the pathogenic activity of the fungus. We did not find a MAT gene, which is consistent with the classification of $P$. Iycopersici as an imperfect fungus, but we observed a significant expansion of the gene families associated with heterokaryon incompatibility $(H \mathrm{I})$.
\end{abstract}

Conclusions: The P. lycopersici draft genome sequence provided insight into the molecular and genetic basis of the fungal lifestyle, characterizing previously unknown pathogenic behaviors and defining strategies that allow this asexual fungus to increase genetic diversity and to acquire new pathogenic traits.

Keywords: Pyrenochaeta lycopersici, Pathogenicity, Genome assembly, Next Generation Sequencing technologies (NGS)

\section{Background}

Pyrenochaeta lycopersici is the soil-borne fungal pathogen responsible for corky root rot (CRR) disease in tomato $[1,2]$. The fungus also infects other Solanaceous species including pepper, eggplant and tobacco, and other cultivated crops such as melon, cucumber, spinach and safflower [3-5]. The pathogen causes significant yield losses in tomato crops, both in the greenhouse and in the field, in many tomato-growing areas of the world. The majority of commercial varieties are susceptible to $P$. lycopersici and sources of partial genetic resistances occur only in wild

\footnotetext{
* Correspondence: massimo.delledonne@univr.it

2Dipartimento di Biotecnologie, Università degli Studi di Verona, Strada le Grazie, 15, 37134 Verona, Italy

Full list of author information is available at the end of the article
}

tomato species [6]. The use of susceptible cultivars combined with continuous cropping and the lack of effective soil treatments has encouraged the rapid spread of CRR disease resulting in fruit yield losses of up to $75 \%[7,8]$. The sequencing of $18 \mathrm{~S}$ nrDNA (SSU) and $28 \mathrm{~S} \mathrm{nrDNA}$ (LSU) indicate that P. lycopersici is an ascomycete in the order Pleosporales, along with other necrotrophic and hemibiotrophic plant pathogens representing genera such as Cochliobolus, Pyrenophora, Phaeosphaeria, Leptosphaeria, Pleospora, Phoma and Didymella [9]. A low grade of genetic variability was shown within $P$. lycopersici isolates, when investigated by RAPD and RFLP analysis [10], and the use of ISSR and AFLP markers $[11,12]$.Little is known about the biology, life cycle and infection structures of this species. A telomorph has not

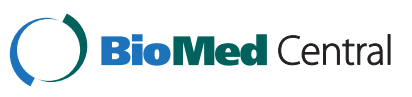


been described and even the anamorph is rare in nature. The latter is characterized by pycnidia containing solitary, mostly branched conidiophores bearing hyaline unicellular conidia (Figure 1A, B). They have never been found on infected tissues in nature and sporulation is difficult to induce in culture. P. lycopersici produces microsclerotia on host plant roots and in artificial medium (Figure 1C), and these are the overwintering structures and primary infective propagules in the soil, remaining dormant but viable for at least 15 years $[3,13,14]$. Under favorable conditions, hyphae germinate from the sclerotia and asymptomatically infect the epidermal cells of host roots (Figure 1D). Approximately $48 \mathrm{~h}$ after initial penetration, the infected host cells die and secondary hyphae develop within them, a stage associated with the appearance of disease symptoms such as tissue browning and necrosis (Figure 1E). The invasion of living host cells by primary hyphae continues at the expanding margins of the lesion, surrounding a central zone of dead cells. P. lycopersici is generally recognized as a hemibiotroph, with biotrophy and necrotrophy probably occurring simultaneously during the later stages of infection, as the necrotic lesions expand and the cells walls are degraded by lytic enzymes [15-17]. Ultimately, the main root is entirely colonized causing the typical corky root lesions, whereas secondary roots often escape infection (Figure 1F) [18]. Only a few P. lycopersici sequences (mostly derived from ITS regions) are deposited in the NCBI database, and little is known about the molecular mechanisms involved in P. lycopersici pathogenicity/virulence and host-pathogen interactions. Recently, a CDNA-AFLP based transcriptomic approach was used to monitor the expression of plant and pathogen genes during a compatible interaction between P. lycopersici and tomato $[19,20]$. This allowed the subsequent isolation and characterization of a $P$. lycopersici endoglucanase which is strongly induced during the infection of tomato roots and whose expression is positively correlated with disease progression [17]. A secreted pathogenicity factor that induces cell death during the penetration of tomato roots has also been identified [21]. Here we report the de novo assembly of the P. lycopersici genome based on Illumina sequencing and the functional characterization of the draft sequence
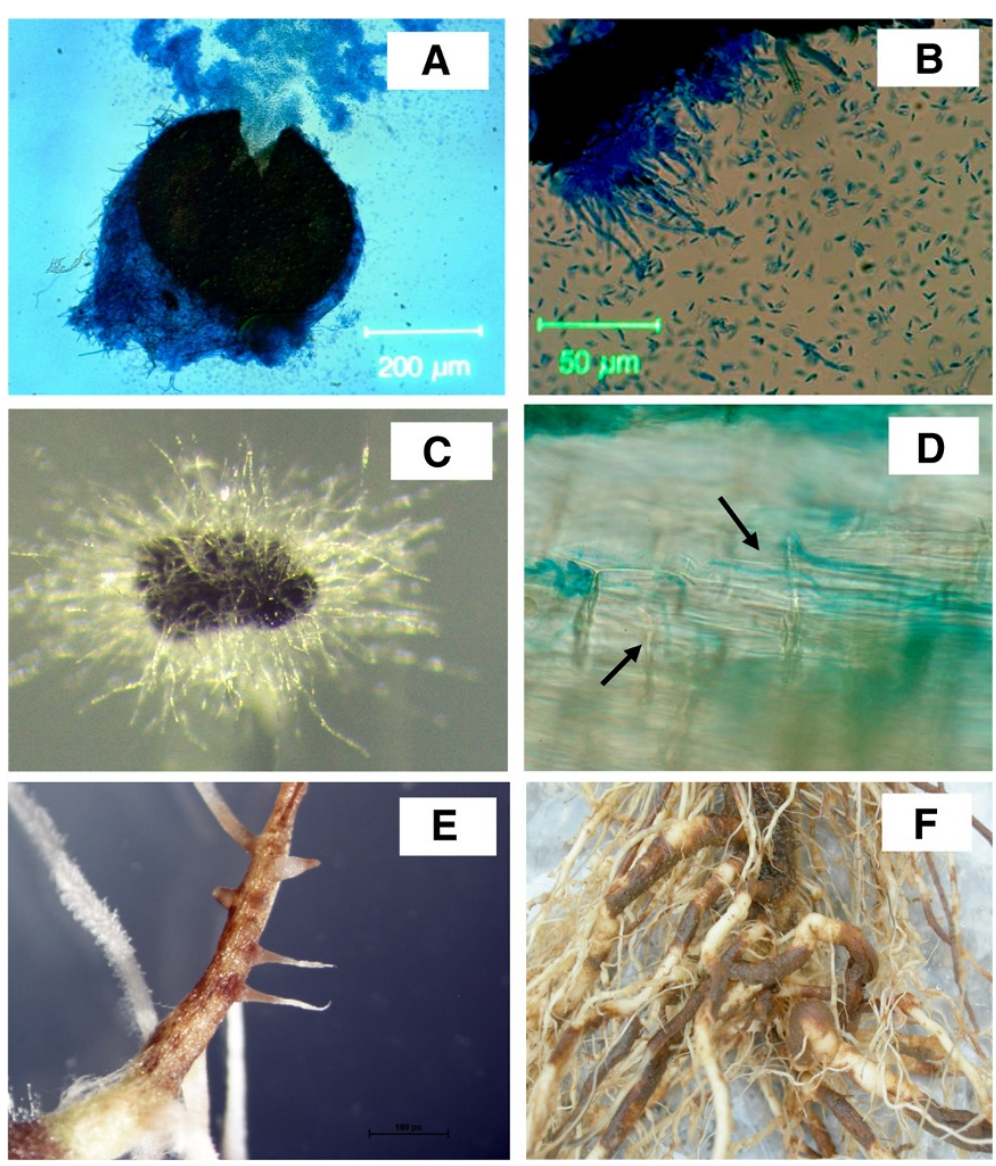

Figure 1 Infection of tomato roots by P. Iycopersici. (A) Light micrograph of a pycnidium with erupting conidia. (B) Light micrograph of conidiophores with conidia. (C) Stereomicrograph of a P. lycopersici microsclerotium germinating on artificial media. (D) P. lycopersici hyphae (black arrows) transformed with GUS + growing within young tomato roots. (E) Symptoms caused by P. lycopersici growing on young tomato rootlets artificially infected with the fungus. (F) Naturally-infected tomato roots with extensive corky root rot symptoms. 
by integrating RNA-Seq data, followed by an in-depth analysis of the virulence mechanisms and potential pathogenicity effectors encoded by this soil-transmitted pathogen.

\section{Results}

Genome sequencing and assembly

Genomic DNA obtained from the virulent P. lycopersici isolate CRA-PAV_ER 1211 was sequenced using Illumina 100-bp paired-end reads. Two libraries were prepared with mean fragment sizes of 460 and 560 bp respectively and sequenced obtaining 85 millions of fragments for a total of $17 \mathrm{~Gb}$, corresponding to approximately 300 -fold coverage of the final assembly.

The $P$. lycopersici genome was assembled de novo using a de Bruijn graph-based (DBG) assembly strategy with a k-mer of 55 (Additional file 1: Figure S1) before reassembly using the overlap-layout-consensus (OLC) method. We chose to use this strategy to take advantage of both the higher efficiency of DBG method in assembling millions of reads and the higher sensitivity of OLC method [22,23]. In fact, the OLC re-assembly of sequences previously assembled with DBG method reduced the total number of sequences by a $40 \%$ (from 11,617 to 7,079 ) while increasing the average contig length by a $60 \%$ (from 4,834 to $7,747 \mathrm{bp}$ ) and not reducing significantly the total number of assembled bases (54.8 Mbps vs. 56.2 Mbps).

The assembly statistics are summarized in Table 1, comprising 7,079 contigs with an N50 of $73.4 \mathrm{~kb}$ for a total sequence of $54.9 \mathrm{Mb}$. The comprehensiveness of the gene space covered by the assembly and annotation procedures was assessed by screening for 248 core eukaryotic genes (CEGs) [24] revealing hits for 238 CEGs (95.97\%) with complete match and 241 with partial match (97.18) (Additional file 2: Table S1).

\section{Gene annotation}

Genes were annotated by a combination of $a b$ initio prediction [25] followed by the reference annotation-based transcript (RABT) assembly of sequences obtained from the RNA-Seq analysis of two P. lycopersici samples grown in vitro and during interaction with tomato $\mathrm{cv}$ Moneymaker, respectively [26]. We annotated 17,411 genes with 27,275 transcripts, among which 9,553 loci were detected by both approaches and 2,797 only by the analysis of RNA-Seq data (Table 1). Thus, while the number of genes might be slightly overestimated because of $a b$ initio prediction limitations, at least $70.8 \%$ of the annotations were supported by experimental evidences. We confirmed that the assembly was able to capture full-length genes by searching the predictions for full open reading frames (ORFs), finding that most of the genes $(80.76 \%)$ contained start and stop codons. The RNA-Seq data were then assembled de novo and the resulting contigs were mapped onto the draft genome.
Table 1 Pyrenochaeta lycopersici genome statistics

\begin{tabular}{|c|c|c|}
\hline & Scaffolds & Contigs \\
\hline Number of sequences & 7,079 & 18,757 \\
\hline Maximum sequence length (bp) & 768,125 & 440,042 \\
\hline Average length (bp) & 7,747 & 2,856 \\
\hline N50 (bp) & 73,363 & 33,727 \\
\hline $\mathrm{N} 90$ (bp) & 313,035 & 127,052 \\
\hline Sequences $>500 b p$ & Scaffolds & Contigs \\
\hline Number of sequences & 5,176 & 10,176 \\
\hline Average length (bp) & 10,479 & 5,037 \\
\hline N50 (bp) & 75,634 & 37,929 \\
\hline N90 (bp) & 315,231 & 10,146 \\
\hline Sequences $>1 \mathrm{~Kb}$ & Scaffolds & Contigs \\
\hline Number of sequences & 4,056 & 5,863 \\
\hline Average length (bp) & 13,174 & 8,217 \\
\hline N50 (bp) & 76,086 & 43,602 \\
\hline N90 (bp) & 315,231 & 130,015 \\
\hline Sequences $>5 K b$ & Scaffolds & Contigs \\
\hline Number of sequences & 1,530 & 1,350 \\
\hline Average length (bp) & 30,926 & 29,077 \\
\hline N50 (bp) & 96,502 & 55,291 \\
\hline N90 (bp) & 369,997 & 139,267 \\
\hline Sequences $>10 \mathrm{~Kb}$ & Scaffolds & Contigs \\
\hline Number of sequences & 784 & 858 \\
\hline Average length (bp) & 53,680 & 41,789 \\
\hline N50 (bp) & 112,715 & 62,806 \\
\hline $\mathrm{N} 90$ (bp) & 391,898 & 139,822 \\
\hline $\begin{array}{l}\text { Total number of assembled } \\
\text { bases (without Ns) }\end{array}$ & \multicolumn{2}{|c|}{$54,841,665 \mathrm{bp}(53,572,698 \mathrm{bp})$} \\
\hline Estimated $x$-fold genome coverage & \multicolumn{2}{|l|}{$217 x$} \\
\hline GC percentage content & \multicolumn{2}{|l|}{$39.40 \%$} \\
\hline Number of annotated gene loci & \multicolumn{2}{|l|}{17,411} \\
\hline $\begin{array}{l}\text { Number of annotated } \\
\text { putative transcripts }\end{array}$ & \multicolumn{2}{|l|}{27,275} \\
\hline Mean gene size (bp) & \multicolumn{2}{|l|}{2,015} \\
\hline Mean exon size (bp) & \multicolumn{2}{|l|}{676.6} \\
\hline Mean number of exons per gene & \multicolumn{2}{|l|}{4.1} \\
\hline
\end{tabular}

From the $31,746,550$ reads, we obtained 27,982 putative transcripts, 27,574 (98.5\%) of which could be mapped onto the assembled genome further validating the comprehensiveness of the gene space represented.

Many of the identified transcripts (75.8\%) were conserved in other species as shown by hits against sequences in the NCBI NR protein database (e-value $<1 \mathrm{E}-0.6)$ and the Uniprot SwissProt Fungi protein database (e-value $<1 \mathrm{E}-0.7$ ). This analysis showed that the most represented species were fungal pathogens and the top four species were phytopathogenic fungi (Additional file 1: Figure S2). Based on 
the identity of the most similar proteins, at least one Gene Ontology term was assigned to 8,507 transcripts. The most represented functional categories are summarized in Additional file 1: Figure S3. We found 3,962 orphan genes (22.8\%) with no matches against known proteins or protein domains [27], which is similar to the proportion of orphan genes found in Sordaria macrospora (22\%) [28] and Macrophomina phaseolina (29\%) [29]. RNA-Seq analysis showed that 1,936 of the 3,962 orphan genes were transcribed and were therefore likely to be functional.

\section{Phylogenetic relationships}

The phylogenetic analysis based on whole genome sequences of $P$. lycopersici and 16 other fungal species with diverse lifestyles (from necrotrophs to biotrophs) is shown in Figure 2. This confirmed that P. lycopersici belongs to the class Dothideomycetes and the order Pleosporales. A neighbor-joining phylogenetic tree, using Rhizopus oryzae as the outgroup, revealed four major clusters representing Saccharomycetes, Leotiomycetes, Sordariomycetes and Dothideomycetes. P. lycopersici appeared to be more closely related to hemibiotrophic and necrotrophic plant pathogens of the genera Leptosphaeria, Pyrenophora and Stagonospora than to biotrophs such as the genera Blumeria and Ustilago.

We performed a pairwise comparison between $P$. lycopersici and Fusarium oxysporum f. sp. lycopersici genomes to assess the genomic distribution of similarity regions.
We choose $F$. oxysporum among the top ranked species (Additional file 2: Table S2) as a complete genome anchored to chromosomes was available for this fungus. As expected the analysis showed regions of similarity at aminoacidic level throughout all the F. oxysporum chromosomes with the exception of the four $F$. oxysporum dispensable chromosomes 3, 6, 14 and 15 (Additional file 1: Figure S4).

\section{Vegetative incompatibility}

Fungi can propagate both by sexual and vegetative reproduction. The latter is controlled by approximately 50 heterokaryon incompatibility (HET) modules in most pathogenic fungi, whereas there was evidence of 284 modules in P. lycopersici (Figure 3a; Additional file 2: Table S4). Accounting for a possible overestimation of the total number of genes by a $40 \%$, based on the percentage of annotations not supported by RNASeq data, the HET protein modules are anyway expanded by 3.9 times, in average, compared to other fungi. Other proteins that are functionally associated with HET contain NTPase, NB-ARC and NACHT domains, which are involved in the regulation of the immune response and are related to apoptosis/programmed cell death in animals and fungi [30]. We identified 53 NACHT proteins encoded by the P. lycopersici genome, which is slightly more than the number in $F$. oxysporum (41) and much higher than in other fungi, which range from 0 in Blumeria graminis to 10 in Colletotrichum

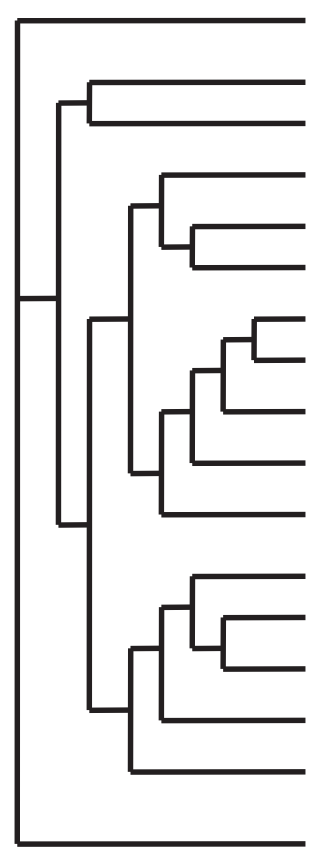

Ustilago maydis

Yarrowia lipolytica

Saccharomyces cerevisiae

Blumeria graminis

Botrytis cinerea

Sclerotinia sclerotiorum

Colletotrichum graminicola

Verticillium albo-atrum

Fusarium graminearum

Neurospora crassa

Magnaporthe grisea

Stagonospora nodorum

Pyrenophora tritici-repentis

Leptosphaeria maculans

Pyrenochaeta lycopersici

Mycosphaerella graminicola

Rhizopus oryzae

\section{BASIDIOMYCOTA}

Saccharomycetes

Leotiomycetes

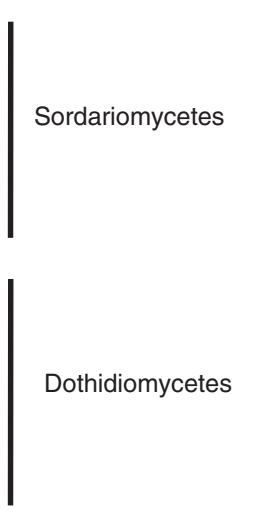

ASCOMYCOTA

ZYGOMYCOTA

Figure 2 Cladogram showing the phylogenetic relationship between $P$. lycopersici and 16 other fungi with sequenced genomes. The unscaled tree was built based on comparison of whole genome sequences of 16 fungi using Rhizopus oryzae as outgroup. 


$$
\begin{aligned}
& \text { A }
\end{aligned}
$$

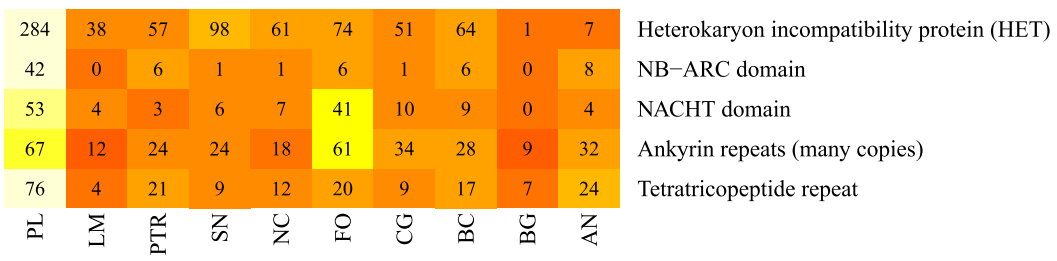

$$
\begin{aligned}
& \begin{array}{lllll|l|l|l|l|l|l|l}
\text { B } & 229 & 150 & 189 & 231 & 114 & 359 & 264 & 194 & 36 & 264 & \text { Major Facilitator Superfamily }
\end{array} \\
& \begin{array}{cccccccccccc}
109 & 67 & 69 & 73 & 62 & 128 & 102 & 93 & 34 & 94 & \mathrm{ABC} \text { transporter } \\
& \sum & \cong & Z & \bigcup & 0 & \bigcup & \bigcup & \bigcup & Z &
\end{array} \\
& \begin{array}{|l|l|l|l|l|l|l|l|l|l|l|l}
\mathbf{C} & 51 & 65 & 58 & 67 & 66 & 126 & 97 & 72 & 18 & 81 & \mathrm{CBM} \\
\hline
\end{array}
\end{aligned}
$$

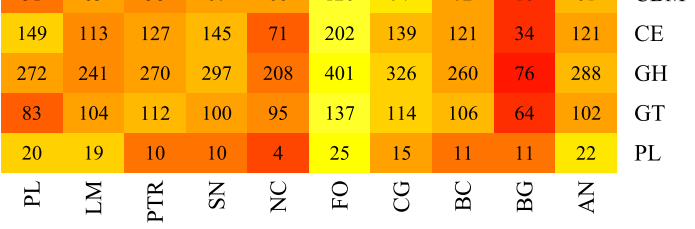

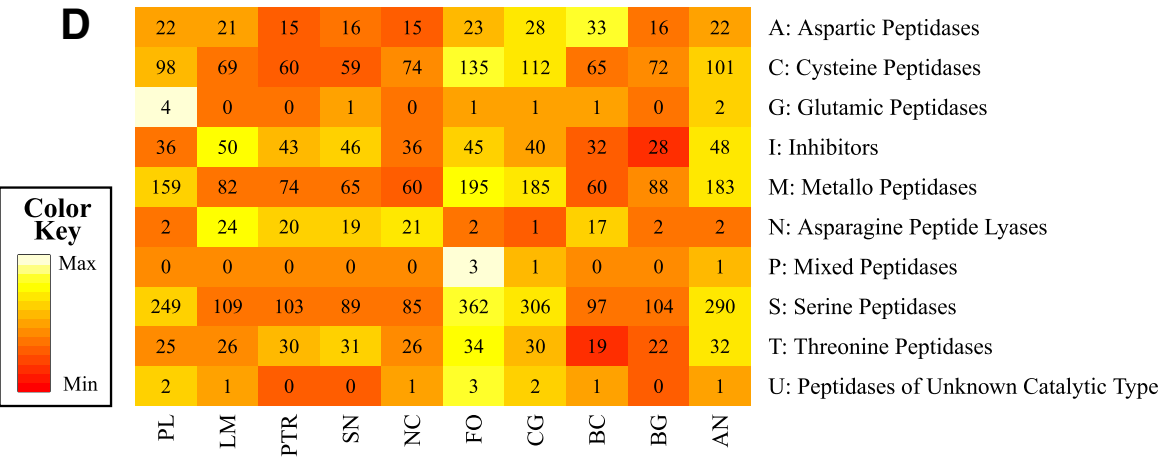

Figure 3 Comparison of repertoires of important fungal protein families. The heat maps compare the number of functional domains identified in P. lycopersici (PL) and nine other fungal pathogens: Aspergillus nidulans (AN), Botrytis cinerea (BC), Blumeria graminis (BG), Colletotrichum graminicola (CG), Fusarium oxysporum (FO), Leptosphaeria maculans (LM), Neurospora crassa (NC), Pyrenophora tritici-repentis (PTR) and Stagonospora nodorum (SN). A) Vegetative incompatibility-related domains. B) Virulence-related efflux pump domains. C) Carbohydrate-active enzymes (CAZymes), GH = glycoside hydrolases; GT = glycosyltransferases; PL = polysaccharide lyases; $C E$ = carbohydrate esterases; $\mathrm{CMB}=$ carbohydrate-binding modules. D) Peptidases by superfamily.

graminicola. The P. lycopersici genome also encoded a significantly greater number of proteins containing ankyrin (ANK) and tetratricopeptide repeats (TPR), which mediate protein-protein interactions among HET proteins. Altogether, the number of HI related proteins includes 522 domains, e.g. more than double the number encoded by the imperfect fungal pathogen $F$. oxysporum. About $75 \%$ of the modules for all the families related to vegetative incompatibility were supported by RNASeq expression data.

\section{Pathogenesis related genes}

We screened the $P$. lycopersici genome sequence against Phi-base, a database that collects pathogenicity, virulence and effector genes from fungi, oomycetes and bacterial pathogens. This revealed that 2,196 (12.6\%) of the P. lycopersici genes were homologous to putative pathogenicity genes (Additional file 3). Comparative analysis with nine sequenced filamentous fungi showed that the gene families with the largest number of shared pathogenicity genes were heterokaryon incompatibility proteins (284), glycoside hydrolase proteins (272), major facilitator superfamily (MFS) type membrane transporters (229), fungal transcription factors (174), protein kinases (170) and cytochrome P450 (125) (Table 2).

The ATP-binding cassette $(\mathrm{ABC})$ transporters and MFS-type membrane transporters were largely represented in the P. lycopersici genome, comprising 109 and 229 modules respectively (Figure $3 \mathrm{~b}$ and Additional file 2: Table S2). Transcriptome analysis showed that $85 \%$ of $\mathrm{ABC}$ modules and $75 \%$ of MFS-type membrane transporters belonged to transcripts expressed. The $P$. lycopersici genome also encoded a large number (125) of cytochrome P450 proteins, as shown for other necrotrophic and hemibiotrophic pathogens such as B. cinerea 
Table 2 Highly represented protein families

\begin{tabular}{|c|c|c|c|c|c|c|c|c|c|c|c|c|}
\hline & AN & BC & BG & CG & FO & LM & NC & PL & PTR & SN & P value* & $\begin{array}{l}\text { Adjusted } \\
\text { P-value** }\end{array}$ \\
\hline Genome assembly size (Mb) & 30.0 & 42.7 & 87.9 & 51.6 & 61.4 & 44.9 & 41.0 & 54.8 & 37.8 & 37.3 & & \\
\hline Number of genes & 10,827 & 16,714 & 7,073 & 12,361 & 21,354 & 12,469 & 9,730 & 17,411 & 12,300 & 12,382 & & \\
\hline Ankyrin repeats & 32 & 28 & 9 & 34 & 61 & 12 & 18 & 67 & 24 & 24 & $8.90 E-04$ & $5.14 E-04$ \\
\hline D-Tyr-tRNA(Tyr) deacylase & 1 & 1 & 1 & 1 & 1 & 1 & 1 & 5 & 1 & 1 & NA & NA \\
\hline DDE superfamily endonuclease & 4 & 12 & 2 & 2 & 13 & 2 & 0 & 89 & 11 & 1 & $1.70 E-08$ & $1.47 E-07$ \\
\hline $\begin{array}{l}\text { Double stranded RNA binding } \\
\text { domain }\end{array}$ & 1 & 2 & 2 & 2 & 2 & 2 & 2 & 7 & 2 & 0 & $1.61 E-06$ & $2.32 E-06$ \\
\hline Mo25-like & 1 & 1 & 1 & 1 & 1 & 1 & 1 & 5 & 1 & 1 & NA & NA \\
\hline NACHT domain & 4 & 9 & 0 & 10 & 41 & 4 & 7 & 53 & 3 & 6 & $1.90 E-04$ & $1.24 E-04$ \\
\hline $\begin{array}{l}\text { NAD-specific glutamate } \\
\text { dehydrogenase }\end{array}$ & 0 & 0 & 0 & 0 & 0 & 0 & 0 & 8 & 0 & 0 & NA & NA \\
\hline NB-ARC domain & 8 & 6 & 0 & 1 & 6 & 0 & 1 & 42 & 6 & 1 & 3.69E-08 & $1.60 E-07$ \\
\hline NPL4 family & 1 & 1 & 1 & 1 & 1 & 1 & 1 & 5 & 1 & 1 & NA & NA \\
\hline Tetratricopeptide repeat & 24 & 17 & 7 & 9 & 20 & 4 & 12 & 76 & 21 & 9 & $2.82 E-07$ & $8.14 E-07$ \\
\hline $\begin{array}{l}\text { Transmembrane alpha-helix } \\
\text { domain }\end{array}$ & 2 & 1 & 0 & 3 & 3 & 1 & 0 & 10 & 4 & 0 & $9.52 E-06$ & $9.15 E-06$ \\
\hline Transposase IS4 & 0 & 0 & 0 & 1 & 17 & 0 & 0 & 11 & 0 & 0 & $1.28 E-02$ & $5.28 E-03$ \\
\hline hAT family dimerisation domain & 0 & 1 & 0 & 0 & 76 & 0 & 0 & 30 & 0 & 0 & 1.30E-01 & 4.17E-02 \\
\hline Helix-turn-helix, Psq domain & 0 & 8 & 0 & 0 & 0 & 0 & 0 & 24 & 0 & 0 & $1.01 E-06$ & $1.75 E-06$ \\
\hline Major facilitator superfamily & 264 & 194 & 36 & 264 & 359 & 150 & 114 & 229 & 189 & 231 & $5.21 \mathrm{E}-01$ & 1.45E-01 \\
\hline Cytochrome P450 & 116 & 120 & 13 & 138 & 157 & 62 & 40 & 125 & 102 & 122 & $2.63 \mathrm{E}-01$ & $7.68 E-02$ \\
\hline $\begin{array}{l}\text { Fungal specific transcription } \\
\text { factor domain }\end{array}$ & 232 & 94 & 20 & 176 & 252 & 100 & 77 & 174 & 96 & 100 & $9.93 E-02$ & $3.31 E-02$ \\
\hline Protein kinase domain & 105 & 94 & 82 & 104 & 146 & 116 & 103 & 170 & 108 & 115 & $2.00 E-04$ & $1.24 E-04$ \\
\hline $\begin{array}{l}\text { Heterokaryon incompatibility } \\
\text { protein (HET) }\end{array}$ & 7 & 64 & 1 & 51 & 74 & 38 & 61 & 284 & 57 & 98 & $1.01 E-06$ & $1.75 E-06$ \\
\hline
\end{tabular}

Selected protein families highly represented in P. lycopersici genome. AN, Aspergillus nidulans; BC, Botrytis cinerea; BG, Blumeria graminis; CG, Colletotrichum graminicola; FO, Fusarium oxysporum; LM, Leptosphaeria maculans; NC, Neurospora crassa; PL Pyrenochaeta lycopersici; PTR, Pyrenophora tritici repentis; SN, Stagonospora nodorum. ${ }^{*}$ The cutoff of significance is set at $\mathrm{P}<0.05 .{ }^{* *}$ Benjamini and Hockberg method was used to calculate adjusted $\mathrm{p}$-values [90].

(120), C. graminicola (138), F. oxysporum (157) and S. nodorum (122).

The P. lycopersici predicted genes also included 597 sequences matching 94 different subfamilies of peptidases (Additional file 2: Table S3). Almost all known peptidase families were represented in the P. lycopersici transcriptome, with DmpA aminopeptidase 1 (P1) as the only exception. The most represented clans were the serine peptidase (S clan) and metallopeptidase ( $\mathrm{M}$ clan), a common feature of fungal pathogens. The comparative analysis of gene families and PFAM domains with several other fungi showed that the number of peptidases in $P$. lycopersici is comparable to other hemibiotrophic pathogens as C. graminicola and F. oxysporum. Metallopeptidase group of aminopeptidases (M1, M18, M24, M28) were highly represented, with 43 domains in P. lycopersici (shown in yellow in Additional file 2: Table S3) compared to 34 and 30 of C. graminicola and F. oxysporum respectively. Analysis of expression data confirmed that 36 of this modules (85\%) corresponded to expressed transcripts. Other metallopeptidase gene families had also undergone expansion in the P. lycopersici genome, including pappalysin, Ste24 and deubiquitinating peptidase (shown in green in Additional file 2: Table S3). A summary is reported in Figure 3d.

\section{Genes involved in carbohydrate degradation (CAZymes)}

Carbohydrate degradation is an important component of fungal pathogenicity and virulence, so we examined the $P$. lycopersici CAZome in detail compared with nine other fungi with complete genome sequences (Additional file 2: Table S6). The P. lycopersici genome encodes 575 CAZyme modules, including 272 glycoside hydrolases, 83 glycosyltransferases, 20 polysaccharide lyases, 149 carbohydrate esterases and 51 carbohydrate-binding modules (CMBs). CE1 and CE10 families of carbohydrate esterases including acetyl xylan esterase (EC 3.1.1.72), cinnamoyl esterase (EC 3.1.1), feruloyl esterase (EC 3.1.1.73), carboxylesterase 
(EC 3.1.1.1), S-formylglutathione hydrolase (EC 3.1.2.12) and sterol esterases are particularly represented (53 CE1 modules out of which $77 \%$ are detected as expressed by RNASeq analysis, 54 modules for CE10 family 73,5\% of which are expressed) similarly to other hemibiotrophs such as C. graminicola and F. oxysporum (Additional file 2: Table S6). Cellulose-degrading enzymes were also well represented in $P$. lycopersici, including seven cellobiohydrolases (GH6), ten $\beta$-1,3-glucanases (GH55) and eight GH105 glycoside hydrolases (unknown mechanism). Finally, the complex of carbohydrate cleaving enzymes was completed by 20 genes encoding polysaccharide lyases, including 13 encoding PL3.

\section{Discussion}

We report here the first genome analysis of a Pyrenochaeta species, the soil-borne filamentous fungus of ascomycete clade Pyrenochaeta lycopersici, which is the etiological agent of tomato corky root rot. The P. lycopersici genome assembly shows that a genome reconstruction approach based uniquely on paired-end Illumina reads is highly effective in reconstructing contigs containing almost full length genes. To validate the genome assembly we assessed the completeness of the gene space represented and we found that, in fact, most of the core eukaryotic conserved genes and the transcripts reconstructed from RNA-Seq data of fungus grown in vitro and during interaction with the host were represented on the assembled genome. Based on published assemblies for the phytopathogens $L$. maculans, $P$. teres, $P$. nodorum and $P$. tritici-repentis the number of annotated genes in $P$. lycopersici is very similar $(17,411$ versus $12,469,11,799,12,382$ and 12,300 respectively) [31-34]. Most of the gene annotations are supported by the presence of a full ORF (about $80 \%)$ and a large fraction of them is validated by RNA-Seq data (70\%), thus representing an high quality resource for the study of functions encoded by $P$. lycopersici genome. It's worth noting that we also identified more than 2,700 genes supported by transcriptomic data but not detected by the prediction algorithm. This is not completely surprising as, even if properly trained, a prediction software will not predict all the genes of an eukaryote organism. An hybrid annotation approach, based on integration of gene predictions and massive parallel sequencing of transcripts, is thus needed to perform a comprehensive annotation of genes in a fungal genome. Overall these data confirm the high quality of the assembly and annotation obtained particularly in terms of the completeness and quality of the gene catalog represented.

The P. lycopersici assembly produced constitutes an invaluable support to understand the unique phenotypical features of this pathogen and allow to investigate the molecular basis of the reproductive behavior and of the mechanisms involved in the pathogenesis. Sexual mating of $P$. lycopersici has never been observed in nature, leading to speculation regarding its reproductive cycle. In agreement with its reproductive behavior based on generating spores (conidia) by mitosis, P. lycopersici apparently lacks of mating-type $(M A T)$ genes that control the choice between sexual and asexual reproduction, suggesting the species is incapable of sexual reproduction. A potential alternative source of genetic variation in $P$. lycopersici is vegetative hyphal fusion controlled by $H E T$ genes, allowing horizontal gene or chromosome transfer potentially followed by non-meiotic recombination. When individuals with the same HET genotype meet, they can produce a viable heterokaryon by anastomosis, whereas individuals with different HET genotypes form a fusion cell which is compartmentalized and undergoes a form of programmed cell death termed vegetative or heterokaryon incompatibility [35]. Although the significance of heterokaryon incompatibility responses is poorly understood [36], it may limit the transmission of mycoviruses and other deleterious replicons between strains [37]. Strong selective pressure is likely to be responsible for the extensive amplification of HET genes and genes with related functions in P. lycopersici, suggesting that HET genes play a key role in the transfer of genetic information in this species, and that a strict regulation of the vegetative reproduction is important for the generation of the variability necessary for the adaptation to the environment and to host defense mechanisms.

From a pathogenetic perspective P. lycopersici is considered a hemibiotrophic fungus because cell wall hydrolytic activity is not detected during the initial infection of tomato plants and few symptoms are visible, whereas later infection involves the secretion of cell wall degrading enzymes that cause the root to collapse $[15,17]$. This was confirmed by our data by the comparison of P. lycopersici sequences with those of other fungi which showed a clear phylogenetic relationship with hemibiotrophic and necrotrophic plant pathogens. Moreover, the analysis of gene functions and comparison of gene sequences with those of other fungi showed that a large fraction of genome is devoted to pathogenetic activity and showed a large overlap of the gene inventory to that of other plant pathogens such as L. maculans, P. teres, $P$. nodorum and P. tritici-repentis.

The first and major barrier to infection by fungal pathogens in plants is the cell wall and cellulose is the main component of plant biomass. Phytopathogenic fungi therefore secrete a cocktail of hydrolytic enzymes known as carbohydrate-active enzymes (CAZymes), which are required to penetrate and then degrade the cuticle and cell wall [38]. The analysis of CAZome of P. lycopersici showed a stronger resemblance to that of hemibiotrophic and necrotrophic plant pathogens such as $C$. graminicola, L. maculans and P. tritici-repentis than to 
that of biotrophs such as B. graminis. In fact, the P. lycopersici genome encoded a large number of cellulosedegrading enzymes, as glycoside hydrolases, required for the complete breakdown of the plant cell wall for successful infection. In particular, the CE1 and CE10 families of carbohydrate esterases, which are required to degrade hemicellulose and thus facilitate the complete hydrolysis of polysaccharides in the cell walls of a wide range of plant species, as well as pectate-lyases (which doubles the number of PLs in P. lycopersici compared to other fungi) were largely represented. This may reflect in an enhanced activity in cleaving pectic polymers, which are more abundant in dicotyledonous plants. Among the glycoside hydrolases, the GH61 family carries out cellulose hydrolysis using a synergic mechanism in concert with canonical cellulases $[39,40]$. The expansion of the GH61 family in P. lycopersici mirrors the expansion of this family in the order Pleosporales [41]. The GH61 gene family is exclusive to fungi and structure-function analysis of some enzymes belonging to this class, showed they cleave cellulose using an oxidative mechanism, and therefore they are not canonical glycoside hydrolases. The new biochemical mechanism proposed for GH61 proteins redefined this class of enzymes as polysaccharide monooxygenases (PMOs) [42,43]. A P. lycopersici endo- $\beta$-1,4-glucanase gene (Plegl1) from the GH61 family is expressed in a manner that corresponds to disease progression $[17,44]$. Plegl1 is thus far the only gene known to be induced in a fungal phytopathogen during infection, suggesting a role in pathogenesis. These data suggest the hypothesis that $P$. lycopersici might have evolved diverse strategies for cellulose digestion.

Other proteins which play an important role in the interaction with the host by detoxifying plant defense compounds are cytochrome $\mathrm{P} 450$ proteins. P. lycopersici, similarly to other hemibiotroph and necrotroph fungal pathogens, shows an high number and an high variety of genes coding for this protein family.

Peptidases are pathogenicity-related enzymes that are secreted to facilitate penetration and colonization of the host by degrading the plant cell wall [45-48] and are required for the degradation of plant defense proteins [49-51]. The P. lycopersici genome encodes a large number of metallopeptidases, covering 10 major peptidase families and 94 subfamilies, in agreement with the general properties of Dothideomycetes genomes, mostly representing hemibiotrophs [41]. The comparison of 18 genomes revealed that Dothideomycetes have a wider range of exopeptidases and endopeptidases than other fungal phytopathogens, including the greatest number of secreted metallopeptidases, but fewer aspartic peptidases (A01) than necrotrophs, saprotrophs and ectomycorrhizal symbionts [41]. The aminopeptidase gene family is the most highly represented among all the metallopeptidase families represented in the $P$. lycopersici genome and it is well documented that bacteria and fungi which secrete aminoproteases are generally pathogenic [52,53].

Another class of proteins which play an important role during host invasion is that of transporters. Transporters import nutrients and export secondary metabolites produced by the fungal pathogens as virulence factors but have a role also in removing toxic compounds. In particular, ABC and MFS transporters are the major families involved [54-56] as they are required to export host-specific toxins (HSTs) and mycotoxins [57-59], remove inhibitory defense compounds such as phytoalexins produced by the host plant [60], and confer resistance to fungicides [61]. Although the virulence of the fungus is not strictly dependent on the abundance of these transporter families [54] is notable that the ABC transporter family in P. lycopersici, together with $F$. oxysporum, is the most diverse and abundant compared to all the other fungi, and is therefore likely to be intimately associated with the virulence mechanism. Overall the analysis of P. lycopersici genome clearly shows that this pathogen evolved its pathogenetic mechanisms through an expansion both of genes involved in the penetration and degradation of the host tissues and by the expansions of gene families necessary to counteract the defense mechanisms of the host.

\section{Conclusions}

$P$. lycopersici genome reveals a significative expansion of specific genes families related both to pathogenesis and to reproduction mechanisms, which suggests that $P$. lycopersici has undergone to a specialization and adaptation process during its evolution. The assembly presented constitutes an important resource to understand the molecular bases of corky root rot and more in general to enrich current knowledge of plant-pathogen interaction mechanisms.

\section{Methods}

\section{Sample and library preparation}

Genomic DNA was isolated from a virulent P. lycopersici isolate (CRA-PAV_ER 1211) grown on Potato Dextrose Agar (PDA) medium, by the method described by Cenis as previously described [62] with the following modifications: $200 \mathrm{mg}$ of mycelium was frozen in liquid nitrogen, pulverized, and incubated in $300 \mu \mathrm{l}$ of lysis buffer (200 $\mathrm{mM}$ Tris- $\mathrm{HCl} \mathrm{pH} 8.5,250 \mathrm{mM} \mathrm{NaCl}, 25 \mathrm{mM}$ EDTA, $0.5 \% \mathrm{SDS}$ ) for $10 \mathrm{~min}$ at $65^{\circ} \mathrm{C}$. We then added $150 \mu \mathrm{l} 3$ $\mathrm{M}$ sodium acetate $(\mathrm{pH} 5.2)$, incubated at $-20^{\circ} \mathrm{C}$ for 10 min and centrifuged at $10000 \times \mathrm{g}$ for $30 \mathrm{~min}$. The supernatant was transferred in a fresh tube and the DNA was precipitated by adding an equal volume of isopropanol, centrifuging at $10000 \times \mathrm{g}$ for $10 \mathrm{~min}$ and washing with $70 \%$ ethanol. Finally the DNA was purified using the NucleoSpin Extract II kit (Macherey-Nagel, Düren, 
Germany). Total RNA from vegetative mycelium grown on PDA medium was extracted using the RNeasy Midi kit (Qiagen, Hilden, Germany). Total RNA from infected tomato roots of cv Moneymaker was extracted using the NucleoSpin RNA Plant 2 kit (Macherey-Nagel) after 8 days post infection (dpi).

Genomic DNA $(6 \mu \mathrm{g})$ was fragmented by nebulization at 35 psi for $6 \mathrm{~min}$. DNA libraries with insert sizes of $400 \mathrm{bp}$ and $560 \mathrm{bp}$ were prepared from $1 \mu \mathrm{g}$ of fragmented genomic DNA using the paired-end TruSeq DNA Sample Preparation Kit (Illumina Inc., San Diego, CA, USA). The library quality was determined using the High Sensitivity DNA Kit (Agilent, Wokingham, UK).

Total RNA samples were assessed for quality using an RNA 6000 Nano Kit (Agilent) and 2.5- $\mu$ g aliquots were used to isolate poly(A) mRNA for the preparation of a non-directional Illumina RNA-Seq library using the TruSeq RNA Sample Prep Kit (Illumina). The quality of the library was checked using the High Sensitivity DNA Kit (Agilent).

\section{Sequencing and data preprocessing}

Libraries were sequenced with an Illumina GAIIx sequencer generating 100-bp paired-end sequences for DNA libraries and 130-bp paired-end sequences for RNA libraries.

The sequences were pre-processed by removing reads with a number of $\mathrm{N}>10$ or with a read quality $<20$ using a custom script. Adapters were clipped using Scythe v0.980 [63] and bases on both 3 ' ends with a quality $<20$ were trimmed using Sickle v0.940 [64], eventually entirely removing the fragment if the length was reduced to $<50 \mathrm{bp}$.

\section{De novo assembly and gene catalog assessment}

The genome was assembled de novo using Velvet v1.1.06 [65] with the following parameters: -exp_cov auto (automatic calculation of expected coverage), -scaffolding (scaffolding of contigs with paired-end reads) and -min_contig_lgth 200 (mimimun contig length = 200). The optimal k-mer length was determined by adjusting the k-mer length from 39 to $67 \mathrm{bp}$ in 4-bp increments and using the k-mer for which the N50 and the maximum contig length reached the highest value (Additional file 1: Figure S1). The resulting contigs were then re-assembled with CAP3 v10/15/07 [66] using standard parameters.

Core Eukaryotic Genes (CEGs) were aligned with assembled genome using BLAST and hits were considered significant when the sequence identity was $>65 \%$.

RNA-seq reads from in vitro mycelia were assembled using Trinity v r2011-11-26 [67] with standard parameters, jaccard clip on and a minimum contig length of $200 \mathrm{bp}$. Assembled contigs were mapped using GMAP [68] with standard parameters.

\section{Gene annotation}

The final assembly was processed by GeneMark.hmmES v2.3e [25] with standard parameters and no a priori information. The genome was masked for repetitive and low-complexity regions with RepeatMasker v open-3.3.0 [69] with standard parameters and a general repeats database. The resulting annotation was refined using TopHat v1.4.1 and Cufflinks v1.2.1 [70] on the two RNA-seq libraries in RABT mode with standard parameters. ORFs were identified for each transcript using CPC v0.9.r2 [71].

\section{Phylogenetic analysis}

A phylogenetic tree based on the comparison of whole genomes of $P$. lycopersici and 16 other fungi was constructed using CVTree v2 [72] at a k-mer length of 7. Rhizopus oryzae was used as the outgroup for building the unscaled tree [73]. The P. tritici-repentis and C. graminicola proteomes were obtained from the Colletotrichum Sequencing Project [74], the L. maculans proteome was obtained from the L. maculans genome project [75], and the B. graminis proteome was obtained from the Blumeria sequencing project [76]. Unless otherwise stated, the remaining proteomes were obtained from the CVtree inbuilt genome database [77].

\section{Functional annotation}

Functional annotation was initiated by using each sequence as a BLAST query [78] against the NCBI Non Redundant database retrieved 2012-09-14 [79] (e-value $<1 \mathrm{E}-0.6)$ and the Uniprot SwissProt Fungi protein database retrieved 2012-04-30 [80] (e-value <1E-0.7). The results were analyzed using Blast2GO [81] and integrated with InterPro results [82]. Conserved protein domains in $P$. lycopersici and all the other fungi considered (AN, BC, BG, CG, FO, LM, NC, PT-R, SN) were identified using HMMer v3.0 [83] to identify homology with proteins in the Pfam-A database (v26.0, 2011-11) [84]. Sequence conservation was considered significant at an e-value threshold <1e-6 for both the entire sequence match and for the independent E-value of the single domain match. CAZymes (v2.0) [85] homology was also inspected using HMMer. Alignments were considered significant at an alignment length $>80$ residues, E-value $<1 \mathrm{e}-5$ and HMM profile coverage $>30 \%$ or alignment length $<80$ residues and E-value $<1 \mathrm{e}-3$ and HMM profile coverage $>30 \%$. BLASTX was used to identify sequences homologous to known pathogenic genes (PHIbase ver 3.2) [86], peptidases (MEROPS ver 9.8) [87], zinc fingers (C2H2 ZNF db, ver. 2007-10-03) [88], MAP kinase sequences from NCBI NR (retrieved 2013-01-30) [79] and membrane transport proteins (TCDB, ver. 2011-July-15) [89] (e-value <1e-10). Sequences with significant hits against membrane transport proteins were also used as BLASTX queries against a G protein-coupled 
receptors database (GPCRDB, retrieved 2013-01-30) [90] and fungi major facilitator superfamily sequences from NCBI NR [79].

Significance of protein families abundance differences between P. lycopersici and all the other fungal plant pathogens (BC, BG, CG, FO, LM, PT-R, SN) was assessed by a 1-sample t-test. Variance was estimated based on protein families abundance data of all the fungal pathogens taken into account (P. lycopersici excluded). P-values were corrected according to Benjamini and Hochberg [91] on the full dataset of comparisons.

Genome coverage has been estimated by mapping the reads on the assembled genome using BWA v. 0.6.2-r126 [92] using default parameters and calculating coverage on a panel of 140 single copy genes.

\section{Data access}

RNASeq reads and transcriptome assemblies have been deposited at the NCBI Sequence Reads Archive (SRA) and NCBI Transcriptome shotgun assembly (TSA) databases respectively and are available under BioProject number PRJNA202292. Genomic reads and genome assembly have been deposited at the NCBI Sequence Reads Archive (SRA) and are available under BioProject number PRJNA202288. Assemblies have been deposited as Whole Genome Shotgun project at DDBJ/EMBL/ GenBank under the accession ASRS00000000. The version described in this paper is version ASRS01000000.

\section{Additional files}

Additional file 1: Figure S1. Genome assembly statistics with Velvet at different $\mathrm{k}$-mer length. A threshold $200 \mathrm{bp}$ was set as the lowest accepted contig length. a) Number of assembled contigs. b) Maximum length of the assembled contigs. c) N50 of the assembly. d) Total sum of bases assembled in the contigs. Figure S2. Most Represented Species in Blast results. The chart reports, for the most represented species, the number of blast hits for P. Iycopersici transcripts. Figure S3. Most Represented GO categories. The chart reports the number of the most represented $\mathrm{GO}$ categories among the assignments to $P$. lycopersici transcripts regarding: A) Process; B) Molecular Function. Figure S4. Comparison with Fusarium oxysporum. Homology regions at aminoacidic level are reported for each chromosome of $F$. oxysporum, in a vertical column, with colors representing the assembled contigs of $P$. lycopersici.

Additional file 2: Table S1. Identified CEGMA ortholog genes. Table S2. Results of identification of major membrane transporter families domains in P. lycopersici and other 9 published transcriptomes. Table S3. Summary counts peptidase of homologs found in P. Iycopersici transcriptome and in 9 published fungi transcriptomes. Table S4. Identification results of Heterokaryon Incompatibility proteins related domains in P. lycopersici (highlighted) and comparison with other fungal genomes. Table S5. Results of CAZyme domains identification comparison between P. lycopersici (highlighted) and other fungal genomes. Table S6. Carbohydrate-degrading enzymes in P. lycopersici (highlighted) and other Ascomycetes.

Additional file 3: Genome annotation. This XLS document contains the annotation of $P$. lycopersici genome.

\section{Competing interests}

The authors declare that they have no competing interests.

\section{Authors' contributions}

MA initiated, designed the research work and wrote the manuscript; AM and AF performed the assembly and the annotation of the genome and the writing of the manuscript; MTV performed the extraction and purification of fungal and plant nucleic acids; PB performed phylogenetic analyses; LO and PT performed sequencing libraries preparation; GZ contributed to the bioinformatic data analysis; Al contributed to design the research work and cared the mycological part; GV and LC contributed to the design of the project and writing the manuscript; . MD designed the project and wrote the manuscript. All authors have read and approved the manuscript for publication.

\section{Acknowledgements}

This research was supported by the Italian national project 'Identificazione di geni implicati nella resistenza e nella patogenicità in interazioni tra piante di interesse agrario e patogeni fungini, batterici e virali' ('RESPAT') funded by MiPAAF and by Fondazione Cariverona (Completamento e attività del Centro di Genomica Funzionale Vegetale), Verona, Italy.

\section{Author details}

${ }^{1}$ Consiglio per la ricerca e la sperimentazione in agricoltura, Centro di Ricerca per la Patologia vegetale, Via C. G. Bertero 22, 00156 Roma, Italy. ${ }^{2}$ Dipartimento di Biotecnologie, Università degli Studi di Verona, Strada le Grazie, 15, 37134 Verona, Italy. ${ }^{3}$ Consiglio per la ricerca e la sperimentazione in agricoltura, Centro di Ricerca per la Genomica e la post genomica animale e vegetale, Via S. Protaso 302, 29017 Fiorenzuola d'Arda (PC), Italy. ${ }^{4}$ Consiglio per la ricerca e la sperimentazione in agricoltura, Unità di Ricerca per la Risicoltura, S.S. 11 per Torino Km 2,5, 13100 Vercelli, Italy.

Received: 20 June 2013 Accepted: 22 April 2014

Published: 27 April 2014

\section{References}

1. Termohlen GP: On corky root of tomato and the corky root fungus. Tijdschr Plantenziekten 1962, 68:295-367.

2. Gerlach W, Schneider R: Nachweis eines Pyrenochaeta Stadiums bei Stammen des Korkwurzelerregers der Tomate. Phytopath Z 1964, 50:262-269.

3. Grove GG, Campbell RN: Host range and survival in soil of Pyrenochaeta lycopersici. Plant Dis 1987, 71:806-809.

4. Infantino A, Di Giambattista G, Porta-Puglia A: First report of Pyrenochaeta lycopersici on melon in Italy. Petria 2000, 10:195-198.

5. Pohronezny KL, Volin RB: Corky Root Rot. In Compendium of Tomato Diseases. Edited by Jones JB, Jones JP, Stall RE, Zitter TA. Minnesota: The American Phytopathological Society; 1991:12-13.

6. Aragona M, Infantino A, Papacchini M: Developing a molecular method for screening the resistance to a pathogen of tomato to contribute to limit the use of toxic chemicals in soil. WIT Trans Ecol Envir 2009, 120:519-524.

7. Campbell RN, Hall DH, Schweers VH: Corky root of tomato in California caused by Pyrenochaeta lycopersici and control by soil fumigation. Plant Dis 1982, 66:657-661.

8. Ekengren SK: Cutting the Gordian knot: taking a stab at corky root rot of tomato. Plant Biotechnol (Tsukuba) 2008, 25:265.

9. de Gruyter J, Woudenberg JHC, Aveskamp MM, Verkley GJM, Groenewald JZ, Crous PW: Systematic reappraisal of species in Phoma section Paraphoma. Pyrenochaeta Pleurophoma Mycologia 2010, 102(5):1066-1108.

10. Infantino A, Aragona M, Brunetti A, Lahoz E, Oliva A, Porta Puglia A: Molecular and physiological characterization of Italian isolates of Pyrenochaeta lycopersici. Mycol Res 2003, 107(6):707-716.

11. Bayraktar H, Oksal E: Molecular, physiological and pathogenic variability of Pyrenochaeta lycopersici associated with corky rot disease of tomato plants in Turkey. Phytoparasitica 2011, 39:165-174.

12. Pucci N, Ferrante M, Infantino A: Study of genetic structure of Italian populations of Pyrenochaeta lycopersici by AFLP analysis. Acta Hortic 2011, 914:121-124.

13. White JG, Scott AC: Formation and ultrastructure of microsclerotia of Pyrenochaeta lycopersici. Ann Appl Biol 1973, 73:163-166.

14. Ball SFL: Morphogenesis and structure of microsclerotia of Pyrenochaeta lycopersici. T Brit Mycol Soc 1979, 73:366-368.

15. Goodenough PW, Kempton RJ: The activity of cell wall degrading enzymes in tomato roots infected with Pyrenochaeta lycopersici and the 
effect of sugar concentrations in these roots on disease development. Physiol Plant Pathol 1976, 9:313-320.

16. Goodenough PW, Kempton RJ, Maw GA: Studies on the root rotting fungus Pyrenochaeta lycopersici: extracellular enzyme secretion by the fungus grown on cell wall material from susceptible and tolerant tomato plants. Physiol Plant Pathol 1976, 8:243-251.

17. Valente MT, Infantino A, Aragona M: Molecular and functional characterization of an endoglucanase in the phytopathogenic fungus Pyrenochaeta lycopersici. Curr Genet 2011, 57:241-251.

18. Shishkoff N: Pyrenochaeta. In Methods for Research in Soilborne Phytopathogenic Fungi. Edited by Singleton L, Mihail JD, Ryush CM. St Paul, Minnesota: APS press; 1992:153-156.

19. Aragona $M$, Infantino A: Expression profiling of tomato response to Pyrenochaeta lycopersici infection. Acta Hortic 2008, 789:257-262.

20. Milc J, Infantino A, Pecchioni N, Aragona M: Identification of tomato genes differentially expressed during compatible interaction with Pyrenochaeta lycopersici. J Plant Pathol 2012, 94(2):283-296.

21. Clergeot P-H, Schuler H, Mørtz E, Brus M, Vintila S, Ekengren S: The corky root rot pathogen Pyrenochaeta lycopersici secretes a proteinaceous inducer of cell death affecting host plants differentially. Phytopathology 2012, 102(9):878-891.

22. Miller JR, Koren S, Sutton G: Assembly algorithms for next-generation sequencing data. Genomics 2010, 95:315-327.

23. Rawat A, Elasri MO, Gust KA, George G, Pham D, Scanlan LD, Vulpe C, Perkins EJ: CAPRG: sequence assembling pipeline for next generation sequencing of non-model organisms. PLoS One 2012, 7(2):e30370.

24. Parra G, Bradnam K, Ning Z, Keane T, Korf I: Assessing the gene space in draft genomes. Nucleic Acids Res 2009, 37:289-297.

25. Ter-Hovhannisyan V, Lomsadze A, Chernoff YO, Borodovsky M: Gene prediction in novel fungal genomes using an ab initio algorithm with unsupervised training. Genome Res 2008, 18:1979-1990.

26. Roberts A, Pimentel H, Trapnell C, Pachter L: Identification of novel transcripts in annotated genomes using RNA-Seq. Bioinformatics 2011, 27:2325-2329.

27. Ekman D, Elofsson A: Identifying and quantifying orphan protein sequences in fungi. J Mol Biol 2010, 396:396-405.

28. Nowrousian M, Stajich JE, Chu M, Engh I, Espagne E, Halliday K, Kamerewerd J, Kempken F, Knab B, Kuo H-C, Osiewacz HD, Pöggeler S, Read ND, Seiler S, Smith KM, Zickler D, Kück U, Freitag M: De novo assembly of a $40 \mathrm{Mb}$ eukaryotic genome from short sequence reads: Sordaria macrospora, a model organism for fungal morphogenesis. PLOS Genet 2010, 6:e1000891.

29. Islam MS, Haque MS, Islam MM, Emdad EM, Halim A, Hossen QMM, Hossain MZ, Ahmed B, Rahim S, Rahman MS, Alam MM, Hou S, Wan X, Saito J a, Alam M: Tools to kill: genome of one of the most destructive plant pathogenic fungi Macrophomina phaseolina. BMC Genomics 2012, 13:493.

30. Daskalov A, Paoletti M, Ness F, Saupe SJ: Genomic clustering and homology between HET-S and the NWD2 STAND protein in various fungal genomes. PLoS One 2012, 7(4):e34854

31. Rouxel T, Grandaubert J, Hane JK, Hoede C, Van De Wouw P, Couloux A, Dominguez V, Anthouard V, Bally P, Bourras S, Cozijnsen AJ, Ciuffetti LM, Dilmaghani A, Duret L, Fudal I, Goodwin SB, Gout L, Glaser N, Linglin J, Kema GHJ, Lapalu N, Lawrence CB, May K, Meyer M, Ollivier B, Schoch CL, Simon A, Spatafora JW, Turgeon BG, Tyler BM, et al: Effector diversification within compartments of the Leptosphaeria maculans genome affected by repeat-induced point mutations. Nat Commun 2011, 2:20210.1038.

32. Ellwood SR, Liu Z, Syme RA, Lai Z, Hane JK, Keiper F, Moffat CS, Oliver RP, Friesen TL: A first genome assembly of the barley fungal pathogen Pyrenophora teres f. teres. Genome Biol 2010, 11:R10910.1186.

33. Hane JK, Williams A, Oliver RP: Genomic and comparative analysis of the class Dothideomycetes. In The Mycota, Volume 14. Edited by Poggeler S, Wostemeyer J. Berlin: Springer-Verlag; 2011:205-226.

34. Pyrenophora tritici-repentis database. http://www.broadinstitute.org/.

35. Hall C, Welch J, Kowbel DJ, Glass NL: Evolution and diversity of a fungal self/nonself recognition locus. PLoS One 2010, 5:e14055.

36. Milgroom MG, Sotirovski K, Risteski M, Brewer MT: Heterokaryons and parasexual recombinants of Cryphonectria parasitica in two clonal populations in southeastern Europe. Fungal Genet Biol 2009, 46:849-854.

37. Tuite MF, Serio TR: The prion hypothesis: from biological anomaly to basic regulatory mechanism. Nat Rev Mol Cell Biol 2010, 11:823-833.

38. Knogge W: Fungal infection of plants. Cell 1996, 8:1711-1722.
39. Harris PV, Welner D, McFarland KC, Re E, Navarro Poulsen JC, Brown K, Salbo R, Ding H, Vlasenko E, Merino S, Xu F, Cherry J, Larsen S, Lo Leggio L: Stimulation of lignocellulosic biomass hydrolysis by proteins of glycoside hydrolase family 61: structure and function of a large, enigmatic family. Biochemistry 2010, 49:3305-3316.

40. Kostylev M, Wilson D: Synergistic interaction in cellulose hydrolysis. Biofuels 2012, 3(1):61-70.

41. Ohm RA, Feau N, Henrissat B, Schoch CL, Horwitz BA, Barry KW, Condon BJ, Copeland AC, Dhillon B, Glaser F, Hesse CN, Kosti I, LaButti K, Lindquist EA, Lucas S, Salamov AA, Bradshaw RE, Ciuffetti L, Hamelin RC, Kema GH, Lawrence C, Scott JA, Spatafora JW, Turgeon BG, de Wit PJ, Zhong S, Goodwin SB, Grigoriev IV: Diverse lifestyles and strategies of plant pathogenesis encoded in the genomes of eighteen dothideomycetes fungi. PLOS Pathog 2012, 8(12):e1003037.

42. Quinlan RJ, Sweeney MD, Lo Leggio L, Otten H, Poulsen JCN, Johansen KS, Krogh KBRM, Jorgensen Cl, Tovborg M, Anthonsen A, Tryfona T, Walter CP, Dupree P, Xu F, Davies GJ, Walton PH: Insights into the oxidative degradation of cellulose by a copper metalloenzyme that exploits biomass components. P Natl Acad Sci USA 2011, 108(37):15079-15084

43. Phillips CM, Beeson WT, Cate JH, Marletta MA: Cellobiose dehydrogenase and a copper-dependent polysaccharide monooxygenase potentiate cellulose degradation by Neurospora crassa. ACS Chem Biol 2011, 6:1399-1406.

44. Aragona M, Valente MT: Endoglucanase expression and virulence in plant fungal pathogens. In The Fungal Cell Wall. Edited by Mora-Montes HM. New York: Nova Publishers; 2013:253-274.

45. Flores A, Chet I, Herrera-Estrella A: Improved biocontrol activity of Trichoderma harzianum strains by overexpression of the proteinase encoding gene prb1. Curr Genet 1997, 31:30-37.

46. Pozo MJ, Baek JM, Garcia JM, Kenerley CM: Functional analysis of tvsp1, a serine protease-encoding gene in the biocontrol agent Trichoderma virens. Fungal Genet Biol 2004, 41:336-348.

47. Suárez B, Rey M, Castillo P, Monte E, Llobell A: Isolation and characterization of PRA1, a trypsin-like protease from the biocontrol agent Trichoderma harzianum CECT 2413 displaying nematicidal activity. Appl Microbiol Biotech 2004, 65:46-55.

48. Viterbo $A$, Harel $M$, Chet I: Isolation of two aspartyl proteases from Trichoderma asperellum expressed during colonization of cucumber roots. FEMS Microbiol Lett 2004, 238:151-158.

49. Carlile AJ, Bindschedler LV, Bailey AM, Bowyer P, Clarkson JM, Cooper RM: Characterization of SNP1, a cell wall-degrading trypsin, produced during infection by Stagonospora nodorum. Mol Plant-Microbe In 2000, 13:538-550

50. Plummer KM, Clark SJ, Ellis LM, Loganathan A, Al-Samarrai TH, Rikkerink EHA, Sullivan PA, Templeton MD, Farley PC: Analysis of a secreted aspartic peptidase disruption mutant of glomerella cingulata. Eur J Plant Pathol 2004, 110:265-274.

51. Thon MR, Nuckles EM, Takach JE, Vaillancourt LJ: CPR1: a gene encoding a putative signal peptidase that functions in pathogenicity of colletotrichum graminicola to maize. Mol Plant-Microbe In 2002, 15:120-128.

52. Goodwin SB, M'barek SB, Dhillon B, Wittenberg AH, Crane CF, Hane JK, Foster AJ, Van der Lee TA, Grimwood J, Aerts A, Antoniw J, Bailey A, Bluhm B, Bowler J, Bristow J, van der Burgt A, Canto-Canché B, Churchill AC, Conde-Ferràez L, Cools HJ, Coutinho PM, Csukai M, Dehal P, De Wit P, Donzelli B, van de Geest HC, Van Ham RC, Hammond-Kosack KE, Henrissat $B$ : Finished genome of the fungal wheat pathogen mycosphaerella graminicola reveals dispensome structure, chromosome plasticity, and stealth pathogenesis. PLoS Genet 2011, 7(6):e1002070.

53. Duplessisa S, Cuomob CA, Linc Y-C, Aertsd A, Tisseranta E, VeneaultFourreya C, Jolye DL, Hacquarda S, Amselemf J, Cantarelg BL, Chiuh R, Coutinhog PM, Feaue N, Fieldh M, Freya P, Gelhayea E, Goldbergb J, Grabherrb MG, Kodirab CD, Kohlera A, Küesi U, Lindquistd EA, Lucasd SM, Magoj R, Maucelib E, Morina E, Murata C, Pangilinand JL, Parkk R, Pearsonb M, et al: Obligate biotrophy features unraveled by the genomic analysis of rust fungi. P Natl Acad Sci USA 2011, 108(229):1669171.

54. Coleman JJ, Mylonakis E: Efflux in fungi: la piece de resistance. PLoS Pathog 2009, 5:e1000486.

55. Morschhauser J: Regulation of multidrug resistance in pathogenic fungi. Fungal Genet Biol 2010, 47:94-106. 
56. Ren Q, Chen K, Paulsen IT: TransportDB: a comprehensive database resource for cytoplasmic membrane transport systems and outer membrane channels. Nucleic Acids Res 2007, 35:D274-D279.

57. Keller NP, Turner G, Bennett JW: Fungal secondary metabolism - from biochemistry to genomics. Nat Rev Microbiol 2005, 3:937-947.

58. Friesen TL, Faris JD, Solomon PS, Oliver RP: Host-specific toxins: effectors of necrotrophic pathogenicity. Cell Microbiol 2008, 10:1421-1428.

59. Walton JD: HC-toxin. Phytochem 2006, 67:1406-1413.

60. Urban M, Bhargava T, Hamer JE: An ATP-driven efflux pump is a novel pathogenicity factor in rice blast disease. EMBO J 1999, 18:512-521.

61. de Waard MA, Andrade AC, Hayashi K, Schoonbeek HJ, Stergiopoulos I, Zwiers LH: Impact of fungal drug transporters on fungicide sensitivity, multidrug resistance and virulence. Pest Manag Sci 2006, 62:195-207.

62. Cenis JL: Rapid extraction of fungal DNA for PCR amplification. Nucleic Acids Res 1992, 20:2380.

63. Scythe homepage. [https://github.com/vsbuffalo/scythe]

64. Sickle homepage. [https://github.com/najoshi/sickle]

65. Zerbino DR, Birney E: Velvet: algorithms for de novo short read assembly using de Bruijn graphs. Genome Res 2008, 18(5):821-829.

66. Huang X, Madan A: CAP3: a DNA sequence assembly program. Genome Res 1999, 9:868-877.

67. Grabherr MG, Haas BJ, Yassour M, Levin JZ, Thompson DA, Amit I, Adiconis X, Fan L, Raychowdhury R, Zeng Q, Chen Z, Mauceli E, Hacohen N, Gnirke A, Rhind N, di Palma F, Birren BW, Nusbaum C, Lindblad-Toh K, Friedman N, Regev A: Full-length transcriptome assembly from RNA-seq data without a reference genome. Nat Biotechnol 2011, 29:1-17.

68. Wu TD, Watanabe CK: GMAP: a genomic mapping and alignment program for mRNA and EST sequences. Bioinformatics 2005, 21:1859-1875.

69. Smit AFA, Hubley R, Green P: RepeatMasker Open-3.0. 1996-2010. [http://www.repeatmasker.org]

70. Trapnell C, Roberts A, Goff L, Pertea G, Kim D, Kelley DR, Pimentel H, Salzberg SL, Rinn JL, Pachter L: Differential gene and transcript expression analysis of RNA-seq experiments with TopHat and Cufflinks. Nat Protoc 2012, 7(3):562-578.

71. Kong $L$, Zhang $Y$, Ye ZQ, Liu XQ, Zhao SQ, Wei L, Gao G: CPC: assess the protein-coding potential of transcripts using sequence features and support vector machine. Nucleic Acids Res 2007, 35:W345-W349.

72. Wang $H, X u Z$, Gao L, Hao B: A fungal phylogeny based on 82 complete genomes using the composition vector method. BMC Evol Biol 2009, 9:195.

73. O'Connell RJ, Thon MR, Hacquard S, Amyotte SG, Kleemann J, Torres MF, Damm U, Buiate E, Epstein L, Alkan N, Altmüller J, Alvarado-Balderrama L, Bauser C, Becker C, Birren BW, Chen Z, Choi J, Crouch JA, Duvick JP, Farman M, Gan P, Heiman D, Henrissat B, Howard RJ, Kabbage M, Koch C, Kracher B, Kubo Y, Law AD, Lebrun M-H, et al: Lifestyle transitions in plant pathogenic Colletotrichum fungi deciphered by genome and transcriptome analyses. Nat Genet 2012, 44:1060-1065

74. Broad Institute of Harvard and MIT. [http://www.broadinstitute.org/]

75. Unitè de Recherche Genomique info. [urgi.versailles.inra.fr]

76. The Blumeria Sequencing Project. [www.blugen.org]

77. LTR Finder. [http://tlife.fudan.edu.cn/cvtree/]

78. Altschul SF, Gish W, Miller W, Myers EW, Lipman DJ: Basic local alignment search tool. J Mol Biol 1990, 215:403-410.

79. NCBI Non redundant protein database. [ftp://ftp.ncbi.nih.gov/blast/db]

80. Uniprot database. [http://www.uniprot.org]

81. Conesa A, Götz S, Garcia-Gomez JM, Terol J, Talon M, Robles M: Blast2GO: a universal tool for annotation, visualization and analysis in functional genomics research. Bioinformatics 2005, 21:3674-3676.

82. Interpro. [http://www.ebi.ac.uk/interpro/]

83. Eddy SR: Accelerated profile HMM searches. PLoS Comput Biol 2011, 7(10):e1002195.

84. PFam. [http://pfam.sanger.ac.uk]

85. dbCAN. [http://csbl.bmb.uga.edu/dbCAN/]

86. PHI-base. [http://www.phi-base.org]
87. MEROPS. [http://merops.sanger.ac.uk]

88. C2H2 ZNF db. [http://kzfgd.pzr.uni-rostock.de:8080/KZGD2007]

89. TCDB. [http://www.tcdb.org]

90. GPCRDB. [http://www.gpcr.org]

91. Benjamini $Y$, Hochberg $Y$ : Controlling the false discovery rate: a practical and powerful approach to multiple testing. J R Stat Soc Ser B 1995, 57:289-300

92. Li H, Durbin R: Fast and accurate short read alignment with Burrows-Wheeler transform. Bioinformatics 2009, 25:1754-1760.

doi:10.1186/1471-2164-15-313

Cite this article as: Aragona et al:: De novo genome assembly of the soil-borne fungus and tomato pathogen Pyrenochaeta lycopersici. BMC Genomics 2014 15:313.

\section{Submit your next manuscript to BioMed Central and take full advantage of:}

- Convenient online submission

- Thorough peer review

- No space constraints or color figure charges

- Immediate publication on acceptance

- Inclusion in PubMed, CAS, Scopus and Google Scholar

- Research which is freely available for redistribution

Submit your manuscript at www.biomedcentral.com/submit
C) Biomed Central 